\title{
RESEARCH
}

Open Access

\section{IDC theory: creation and the creation loop}

Tak-Wai Chan ${ }^{1}$, Chee-Kit Looi ${ }^{2}$, Ben Chang ${ }^{3 *}$ (D), Wenli Chen², Lung-Hsiang Wong ${ }^{2}$, Su Luan Wong ${ }^{4}$, Fu-Yun Yu ${ }^{5}$, Jon Mason ${ }^{6}$, Chen-Chung Liư ${ }^{7}$ Ju-Ling Shih ${ }^{1}$, Ying-Tien Wu', Siu-Cheung Kong ${ }^{8}$, Longkai Wu ${ }^{2}$, Tzu-Chao Chien ${ }^{9}$, Calvin C. Y. Liao ${ }^{10}$, Hercy Cheng ${ }^{11}$, Zhi-Hong Chen ${ }^{12}$ and Chih-Yueh Chou ${ }^{13}$

\footnotetext{
*Correspondence: bchang.tw@ gmail.com

${ }^{3}$ Graduate Institute of Learning and Instruction, National Central

University, Taoyuan City, Taiwan

Full list of author information is

available at the end of the article
}

\begin{abstract}
The interest-driven creator (IDC) theory is being developed as a group endeavor by Asian researchers to articulate a holistic learning design theory for future education in Asia. The theory hypothesizes that students, driven by interest, can be engaged in the creation of knowledge (generating ideas and artifacts). By repeating this creation process in their daily learning routines, they will excel in learning performance, develop twenty-first-century competencies, and form creation habits. We hope that with such practices in education, our future generations will ultimately become lifelong interestdriven creators. In IDC Theory, there are three anchored concepts, namely, interest, creation, and habit. Each anchored concept comprises three component concepts which form a concept loop. For example, the creation loop consists of three component concepts_-imitating, combining, and staging. Imitating is concerned with taking in (or inputting) an abundant amount of existing knowledge from the outside world to form one's background knowledge. Combining refers to delivering (or outputting) new ideas or artifacts prolifically by synthesizing existing information encountered in the world and thoughts arising from the students' background knowledge. Staging relates to frequently demonstrating the generated ideas or artifacts to the relevant communities and receiving feedback from these communities to improve the novelty and value of the demonstrated outcomes while gaining social recognition and nurturing positive social emotions. This paper focuses on describing the three components of the creation loop. We provide three case studies to illustrate the creation loop at work, as well as how it intertwines with both the interest and habit loops in supporting students to develop their creation capabilities. In presenting this iteration of the creation concept, an anchored concept in IDC theory, we acknowledge the roles played of imitation, combination, and staging in different learning and education contexts - indeed, there are multiple theories that inform and intersect with it.
\end{abstract}

Keywords: Interest-driven creator (IDC) theory, Creation, Creativity, Interest, Habit, Imitating, Combining, Staging

\section{Introduction}

Learning, as defined both by the Oxford English Dictionary and the neuroscience textbook by Bear, Connors, and Paradiso (2016, p. 824), is the acquisition of knowledge or skills. It is more broadly defined as the 'acquisition of knowledge, skills, and attitudes' (ISO, 2008). However, to prepare our next generation to face the unpredictable future, learning must go beyond acquisition. They must develop the agency and ability of creating their own ideas and artifacts. In the interest-driven creator (IDC) theory, we

(c) The Author(s). 2019 Open Access This article is distributed under the terms of the Creative Commons Attribution 4.0 International License (http://creativecommons.org/licenses/by/4.0/), which permits unrestricted use, distribution, and reproduction in any medium, provided you give appropriate credit to the original author(s) and the source, provide a link to the Creative Commons license, and indicate if changes were made. 
view learning as a creation process, and vice versa. When we learn, we generate ideas and concepts expressed through some media, or we produce some tangible artifacts that can be manipulated in the physical world. Conversely, when we create ideas or artifacts, the experience alters and enriches our background knowledge; in other words, we learn. The preliminary work giving an overview of IDC theory and highlighting its origin with some history was published in 2018 (Chan et al., 2018).

In the design of learning activities in IDC theory, the first consideration is the nurturing of interests. When learning becomes interesting for students, they will focus their attention on learning, spend time and energy, make effort without feeling that they are making effort, enjoy learning, and, consequently, excel in learning performance. Despite that, creation is the actual learning process. This means that students will intend to create something worth sharing with their peers, feel a sense of achievement, and take pride in the creation. Whether we can make a learning process a creation process as well as nurturing the interest of students, depends, however, on how we design the learning activities. But what does a learning activity constitute so that it can become a creation process and ultimately an interest of the students? This paper is second in a three-part series of IDC theory which examines in detail the subject of the second anchored concept-creation. Specifically, this paper is part of a series that includes two other papers on:

- Interest, which examined the first anchored concept of IDC emphasizing the significance of promoting student learning through interest,

- Habits, which focuses on the third and final anchored concept of IDC where learning habits are built through interest-driven creation activities undertaken as daily learning routines.

Certainly, everyone can create. Creation is not some mysterious capability limited to a small group of people labeled as geniuses. Even a baby can create. For example, when a baby begins to talk to its mother, every utterance the baby makes is created "on the fly" by combining different words, and the baby's mother understands or guesses what is being said. When looking back at the long history of human development, we know humans are naturally genuine creators. As hunter-gatherers, our ancestors used primitive tools, such as stone axes. They created tools by observing their forefathers and mimicking their actions. In this creation process, they communicated via gestures (a primordial language) or oral language (when it was developed). To inherit knowledge and skills, the younger generations saw different tools and observed different ways of creating tools before they set about creating their own. Sometimes the tools they created might be different from what they had seen before. In fact, every act was a different act, combining what an individual knew already with what that individual perceived from the outside world through various senses: visual, audio, tactile, and others. From the ancient to the modern times, humans have been creating ideas and things.

Now, advanced technology is speeding up the creation process. In Asian educational contexts, however, the natural disposition for creation has been distorted by the current dominating examination-driven education. Fortunately, with technological support, we can revive this creation culture, propelling schools forward to meet the needs of future society. In fact, fostering knowledge creation capability in schools has been advocated 
by a number of researchers (Scardamalia \& Bereiter, 2003, 2006; Tan, So, \& Yeo, 2014). They develop theory, pedagogy, and technology support for knowledge-building by engaging students in theorizing, generating, improving, and advancing ideas. Students are all contributors to a shared goal; all ideas can be improved upon; and all participants have a sense of ownership in the advancement of knowledge development.

Before we proceed further, let us review the meaning of the words create, creation, creator, and creativity. The word create derives from the Latin creare. The online Oxford Dictionary ${ }^{1}$ defines create as "to bring something into existence," creation as "the action or process of bringing something into existence," and creator as "a person or thing that brings something into existence." Thus, the action of producing a product by a factory worker and the process of having a child borne by a pregnant woman can both be regarded as creations, and both the worker and the woman can be considered creators. Creativity, on the other hand, is defined as the use of imagination or original ideas to create something.

With our view of learning as creation, we decompose the anchored concept creation into three component concepts_-imitating, combining, and staging-forming the creation loop (2015, Fig. 1) ${ }^{2}$. This implies that the design of a creation activity can be decomposed in terms of the design of knowledge-building activities. Furthermore, this also allows us to focus on how to make each component an interest of students. As noted in Chan et al. (2018), each component activity can be an individual or group activity.

Imitating, the first component, concerns inputting: taking in, absorbing, assimilating, appropriating or gaining copious existing knowledge to expand on background knowledge. Combining, the second component, deals with outputting: generating, producing, developing, or constructing creations, which are ideas or concepts, methods or procedures, artifacts or tangible things. Staging, the third component, aims to enable the students to improve the quality of their creations as well as to receive social recognition by explaining, demonstrating, and receiving feedbacks through discussion with their community. It should be noted that the creation loop is a repeating cycle where the three components occur in a sequence but the corresponding activities may not take place in a continuous period of time. For example, imitating may take place twice in one morning while combining occurs in the next day with staging happening in the following week.

\section{Imitating: absorbing abundant existing knowledge}

It is impossible to learn every existing knowledge or skill by recreating it again or trial and error. For some tasks, it is too costly to learn through trial and error. Learning to hunt or swim by trial and error, for example, may cause fatal mistakes. Conversely, learning by imitating a model is a desirable, effective, and efficient way of acquiring existed knowledge or skills. Obviously, a source of competent models is the expert or the teacher. Modeling, a kind of learning by observation, is the first step of cognitive apprenticeship (Collins, Brown, \& Newman, 1989). It refers to an expert's demonstration so that the students can observe how the expert performs the task in authentic

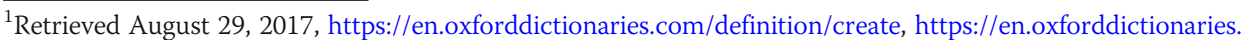
com/definition/creation, https://en.oxforddictionaries.com/definition/creator

${ }^{2}$ This paper is a substantial expansion of the initial descriptions of the creation loop by Chan, Looi, and Chang (2015) and Chan et al. (2018).
} 


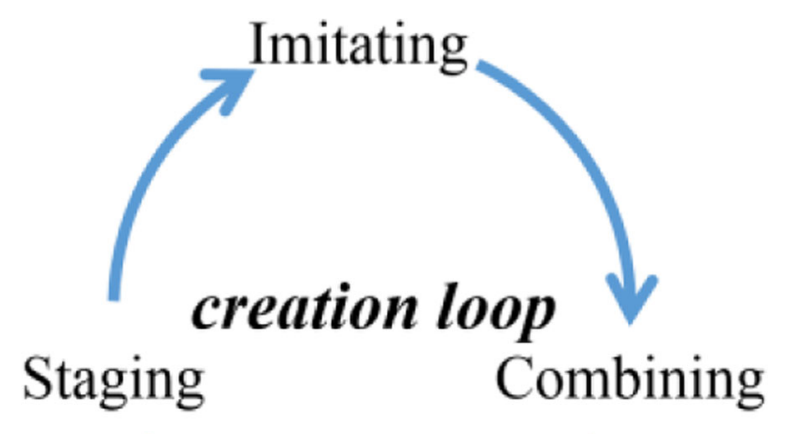

Fig. 1 The creation loop

settings. Through modeling, the expert can externalize the usual internal process of performing the task, help the students build a conceptual model of how to achieve the task, enable them to understand and follow the expert's ideas, methods, manners, or ways of doing things. Even working in an organization or a community of practice in the real world, new members learn from core members through imitative behavior, following a form of peripheral participation starting from the outside and moving to the inside (Wenger, 1998).

\section{Imitating}

Imitating, the first component of the creation loop, which is concerned with taking in plentiful existing knowledge, is the preparation process of creation. Creators must know a lot before they are able to create something deemed valuable by their community. Those who know little about a domain can hardly create anything novel and useful in the domain. Edison, Einstein, Mozart, and Zhang Heng ${ }^{3}$ were all "experts" in their own fields, having acquired abundant knowledge about their respective fields before demonstrating their creations. The same is true about babies who have heard numerous utterances from their mothers before they can create their own. When interacting with the outside world, the richer our background knowledge, the greater the chance the incoming new knowledge will connect to our related background knowledge, leading to a burst of new ideas. In order to create, we need to acquire a breadth of knowledge through various experiences to form our background knowledge.

There are several basic ways of acquiring knowledge (Gazzaniga, Heatherton, \& Halpern, 2016, p. 223-224). The simplest way is through a change of response to a single stimulus after repeated exposure to that stimulus. For example, one may begin to ignore the noise of aircraft after living close to an airport for some time. Another way is to understand the relationship between two stimuli or events that take place one after the other. For example, one may associate the feeling of thirst with drinking water or relate a dangerously moving vehicle with an accident. The third way is through

${ }^{3}$ Zhang Heng was an astronomer, mathematician, scientist, engineer, inventor, geographer, cartographer, artist, poet, statesman, and literary scholar (see https://en.wikipedia.org/wiki/Zhang_Heng). 
observation: imitating behaviors or skills by observing how others behave. Observation means to perceive or to examine either in physical reality or through printed or digital media. For example, by watching others in person or in the media, students may adopt good or bad behaviors. Learning by observation (discussed further later) is a form of imitational learning.

While the present-day emphasis on creativity and innovation can easily devalue the role of imitation in learning, imitation, which is innate and prevalent, is a natural way of acquiring real-world existing knowledge. Even newborn babies are able to imitate adult's gestures (Meltzoff \& Moore, 1977). Toddlers, before they develop language skills, also demonstrate imitative behavior. For adults and society as a whole, imitation behavior has even more far-reaching consequences. More recently, scientists have discovered the mechanism of imitation in our brain-a special class of brain cells, called mirror neurons (di Pellegrino, Fadiga, Fogassi, Gallese, \& Rizzolatti, 1992; Rizzolatti \& Fabbri-Destro, 2010). As Iacoboni (2008, p. 10) puts it: "The simple fact that a subset of the cells in our brains-the mirror neurons-fire when an individual kicks a soccer ball, sees a ball being kicked, hears a ball being kicked, and even just says and hears the word "kick" leads to amazing correspondences and new understandings." The discovery of mirror neurons holds the potential to broaden our understanding of learning, language, empathy, and possibly other human mental abilities (Iacoboni, 2008).

Our dramatic capacity of imitation forms the basis of human culture, which sets us apart from other species, including apes (Rizzolatti, 2014). Through non-genetic means, especially copying or imitating, social practices, languages, ideas, and belief systems are transmitted from generation to generation, producing different cultures throughout the world (Dawkins, 1976). From a socio-cultural perspective, learning means becoming a member of the community via legitimate peripheral participation (Lave \& Wenger, 1991), which is akin to observing and imitating the practices of the core members of the community. Joining the community and moving from the periphery towards the core would involve cycles of imitating and engaging in the real practice of the community through scaffolding by the more knowledgeable members of the community.

Studies of imitation have a long history from areas such as social psychology (Allport, 1924), animal behavior (Holt, 1931), and developmental psychology (Piaget, 1951) and others. From the social cognition perspective, a notable study perhaps is observational learning ascribed by Albert Bandura (1971, 1986, p. 47-105). Noticing that "virtually all learning phenomena, resulting from direct experience, can occur vicariously by observing other people's behavior and its consequences for them (1986, p. 19)," he put forward four constituent processes governing observational learning: (1) attention: observers cannot learn unless they attend to, and so they must choose what they are interested to observe; (2) retention: observers can benefit from observing the model if they can remember at some later time, usually involving imaginal and verbal representational systems; (3) production: observers are able to produce at least parts of what they have observed (note that observers may not have yet acquired all observed knowledge or skills); (4) motivation: observers need motivation to recreate what they have observed. In IDC Theory, both attention and motivation are considered separately by the interest loop (the MSSR example described later in this paper illustrates such consideration). In addition, in the habit loop, the cuing environment is intended to provide a daily supportive environment for students to perform what they have observed. 
Imitational learning

With so many studies of imitation, for design purposes, we feel that there is a need for a simplified definition of learning through imitation. We define imitational learning as a process that requires something or someone to serve as a model, and it consists of two sub-processes: observation of the model and recreation of the model based on the observation. Besides mimicking somebody's actions, voices, gestures, or manner, a "model" for imitation could be a character in a book or a movie, a method or procedure described in a book, depicted in a picture or in digital forms, or illustrated in a video, or some artifact or tangible object. "Observation" is concerned with inputting information by perceiving and examining it through our senses (sight, hearing, etc.) from the model, either in physical reality or through printed or digital media. After observation, "recreation" is the development of something through delivering information, performing actions, or making things that resemble the model. This recreation reinforces the acquisition of what is observed.

The immediate recreation of the model may not be necessary in imitational learning. What is observed has become part of one's background knowledge, which is then retrieved when being recreated at a later stage. For effective observation, however, students need a competent model to follow. For example, for children to learn their mother tongue, they need to be exposed to the utterances of adults who serve as their models. In general, imitational learning occurs naturally, especially when what is observed is appealing to the student.

In the process of recreation, if the delivered output replicates the model with a high degree of resemblance, then this is a pure form of imitation. Such high-resemblance imitational learning is usually demanded when learning about sports, learning to dance, or learning the speech sounds of a language. However, in many cases, the exhibited performance or produced output bears little resemblance to the model, and yet the students still find that their product makes sense to themselves. This is because in reproducing the model, we are likely to connect it with thoughts and experiences from our background knowledge, generating something different from the original model. Therefore, imitational learning represents a spectrum of activities that differ according to the degree of resemblance between what is observed and what is recreated.

\section{Summary of imitating}

In summary, imitating is an essential way for preparing creation, that is, students have to take in abundant existing knowledge through imitation to form their background knowledge before they can create things that are significant or add value to their lives. It is important to note that observation per se is a form of imitational learning, in which the immediate follow-up recreation of the model after observation is not required until an evoking situation arises. Thus, the act of observing entails lower levels of cognition such as remembering and understanding. When the application of what has observed to a new situation is needed, the recreation process is evoked. Therefore, the three lower-level educational objectives of Bloom's taxonomy (Anderson \& Krathwohl, 2000; Bloom, 1956)_remembering, understanding, and applying-can be regarded as imitation of different extents. In general, imitation demonstrates a spectrum of learning: at one end of the spectrum, students may mirror what other 
people do or replicate the model; at the other, they may recreate things bearing little resemblance to the model.

The aforesaid summary suggests that creation occurs only after imitation. However, there may be a concern whether imitation prohibits novel creation. First of all, in applying IDC theory, students should not be asked to imitate and create at the same time. Imitation, the natural and effective way of acquiring existing knowledge, is to enrich background knowledge. The richer background knowledge one has acquired, the more curious about the outside world one will be. The more easily one connects what one does not know about the outside world to what one has already known before (background knowledge), the more likely one finds the possibility of or needs for creation in order to bridge the knowledge gap. This is why imitating serves as the preparation process of creation. Combining, however, is the actual process of creating something new; that is, the outputted creation differs from what the creator has known before, at least to some extent. The combining process synthesizes the incoming new information from the outside world with the creator's background knowledge. This is the subject of the next section.

\section{Combining: generating ideas or things through synthesizing prolifically}

After a period of imitational learning, students may reach a point where they conceive some ideas for some creations they want to develop. Such creations may be hinted at by the teacher, possibly in the form of a challenge to the students. We call such creations targeted creations. To achieve these, students will go through a process of combining. In fact, Bloom's taxonomy has already delineated the pathway of the creation process from imitating (remembering, understanding, and applying) to combining (analyzing, evaluating, and creating). Combining, the second component of creation, is the process in which students generate new ideas or artifacts prolifically by a series of transformations and integrations of existing ideas or artifacts with their own ideas from background knowledge (Knobel \& Lankshear, 2008; Lessing, 2008; Liu, Chen, Lin, \& Huang, 2017).

First of all, what is creation in the educational context? Being the action or process of bringing something into existence, drawing or writing is a creation; defining a problem or solving a problem is a creation; discovering an explanation for a scientific phenomenon is a creation; designing something useful based on observing what people need is a creation; and there are many others. Of course, creation has many meanings in various approaches to learning, ranging from learning by doing, knowledge building, constructionism, and the more recent maker space and computational thinking movement. All these take somewhat different perspectives and nuances in terms of learning as creation, but share one common underlying idea-combination-bringing different ideas and things together to form something. Combining is at the core of the creation process.

\section{Combining}

To create a new concept or artifact, students may look at the existing concepts or artifacts and decide what features to select or abandon. To synthesize those selected features, the students may alter some of them, generate ideas or yield fresh insights, 
then come up with some extraordinary ways of combining ideas, and finally deliver a new concept or artifact. A combination is usually not only a summation; it may deliver emergent features that do not exist in individual concepts or artifacts (Ward \& Kolomyts, 2010). That is why a composer may rearrange notes of a musical scale to create a new melody, and an entrepreneur may reorganize salient components, products, and services to create a successful new product or business model.

Combining therefore underlies not only creation but also creativity. Here, we give a short account of creativity. The word "creativity" was only invented in the late nineteenth century (Sawyer, 2012, p. 19). Studies on creativity began in the mid-nineteenth century, as indicated by the works of the Italian psychiatrist, Cesare Lombroso (1891) and the British scientist and naturalist, Francis Galton (1869), but not much serious research on creativity took place in the late nineteenth century or the early twentieth century. Interest in the study of creativity was revived by the presidential address given by Joy Paul Guilford (1950) when he was the president of the American Psychological Association. What do modern researchers mean by creativity? Authors of different chapters in the Handbook of Creativity (Sternberg, 1999) expressed a common consensus from slightly different points of view. Overall, they concurred that creativity involves the creation of something that is novel, new, innovative, or original as well as valuable, useful, appropriate, or adaptive to a relevant community. However, many ideas and things are new but not valuable. For example, a square wheel is novel but not valuable. Similarly, many existing ideas or things are valuable but no longer new, for example, brushing one's teeth in the morning. Thus, something is creative only if it is both novel and valuable.

However, utter novelty or genuine originality is rare. Nothing comes from nowhere. New things are built on from old things. Most creations that seem to be novel are actually combinations of some basic elements of existing concepts, through a series of analysis, decomposition, and conversion of these elements (Knobel \& Lankshear, 2008; Lessing, 2008; Liu et al., 2017). Thus, for educational purposes, especially for helping students to achieve, novelty is treated as a relative term, rather than an absolute one. This means that an idea or artifact is novel to a student if the idea does not form part of the student's background knowledge. An idea is novel to a student community if the idea has not been heard about before by the community. Seldom are two things exactly the same when they emerge in different times and contexts. The same applies to the value of an idea or artifact because the value is judged by the relevant community (Csikszentmihalyi, 1996).

To nurture students to be creators, the first concern is whether they are able to create and not whether their creations are creative. The second concern is quantity: whether the creators can create prolifically and the third concern is then quality. This means that quantity precedes quality-from none to one, from few to plenty, and from ordinary to excellent. As Linus Pauling, a two-time Nobel laureate, puts it (Sawyer, 2013, p. 129), "the best way to have a good idea is to have a lot of ideas." In fact, most renowned intellects, inventors, or artists, including Edison, Picasso, the Beatles, and numerous others, are prolific creators. Simonton (1988, pp. 88-91) noticed that those who outputted prolifically were the creators most likely to have delivered a significant work. Weisberg (1986) also found that geniuses generated more wrong ideas than average people simply because they generated more ideas overall. 
It is interesting to examine the role of background knowledge and models in the process of creating a new product by eminent creators. In explaining why people can combine existing things into new products, Steve Jobs pointed out that (Cohen, 2016, p. 103) "When you ask creative people how they did something, they feel a little guilty because they didn't really do it. They just saw something (models)... They were able to connect experiences they've had (background knowledge) and synthesize new things... They were able to do that because they've had more experiences or thought more about their experiences than other people." Jobs emphasized the availability of a model and its connection to background knowledge.

However, it is also true that some great creations may have no model at hand. For example, the legendary Frenchman, Henri Poincaré (2015/1908, p. 387) recollected his mathematical discovery process, “... every day I seated myself at my work table, stayed an hour or two, tried a great number of combinations and reached no results. One evening, contrary to my custom, I drank black coffee and could not sleep. Ideas rose in crowds; I felt them collide until pairs interlocked, so to speak, making a stable combination. By the next morning I had established the existence of a class of Fuchsian functions." Poincaré's creation was purely based on his mental combination-reinterpreting concepts or thoughts by breaking them down into elements and recombining these elements in a surprising way to achieve a goal (Kounios \& Beeman, 2015, p. 9). What Poincaré mainly relied on was his enormous background knowledge, or we can say that most related mathematical concepts had been previously absorbed as part of his background knowledge.

There are cases where the provision of multiple models plays a critical role. Rothenberg (1996) noticed that many literary and artistic prize winners and Nobel laureates in sciences are able to conceive and use multiple opposites or antitheses to inspire breakthrough ideas. In this process that Rothenberg called "Janusian thinking," they continuously and simultaneously separate and connect elements in opposites in the same mental space, leading to the articulation of new identities and finally producing a novel combination. Janusian thinking can be viewed as a subset of the Russian Theory of Inventive Problem Solving (TRIZ) techniques for generating a new idea or product (Altshuller, 1992).

For many students, when exposed to only one model to learn it is highly likely that their creation will resemble that model. In other words, students who have not acquired a high level of competency will only be capable of replicating rather than creating something new. Thus, the provision of multiple models, at least at the beginning, scaffolds creation. Going back in time, it is highly likely that our ancestors in the Stone Age had also stumbled upon multiple axes before they were able to create their own. Drawing parallels to modern times, all too often we encounter multiple models. For example, we can find chairs of various designs in our house. Also, with the proliferation and support of social media, individuals are now able to create new artifacts through the integration and reuse of existing intellectual works under certain agreements such as Creative Commons or open-source-like development (Liu, Tao, Chen, Chen, \& Liu, 2013). Such development in the digital age has certainly encouraged creative people to share their work freely for the benefit of mankind.

To engage students in a combining activity, we recommend that the targeted creation be initiated by students themselves and be thought-provoking (e.g., producing 
something exciting, seeking an answer to a curious question, or solving a challenging problem). Also, the models provided need to be intriguing to the students (e.g., each model has some unique features or a story behind it).

\section{Summary of combining}

We may summarize learning by combining as an activity in which students produce something that requires (1) conceiving or defining a targeted creation, (2) examining multiple models (teachers, mentors, books, articles, events, tangible objects, etc.), (3) analyzing and evaluating some key features of the models, (4) altering these features, if needed, and (5) putting these features together to produce something of their own that can be considered new and valuable to the affiliated community. All these steps work alongside ideas from the students' background knowledge. Such learning per se also reorganizes, deepens, and broadens the background knowledge at the same time.

It should be noted that learning by creating is not limited to the aforementioned ascription. Various versions exist. For example, SCAMPER (Eberle, 1972) represents a list of processes-substitute, combine, adapt, magnify or modify, put to other uses, eliminate, rearrange or reverse-for coming up with new ideas. Puentedara (2010) proposes the SAMR (substitute, augment, modify, and redefine) model. Other authors such as Michalko (2001), Linkner (2011), and Sawyer (2013) propose different processes. Design thinking (Brown, 2009), inquiry-based learning (Pedaste et al., 2015), project-based learning (Blumenfeld et al., 1991), problem-based learning (Hmelo-Silver, 2004), or any learning through discovering and solving complex problems, all assume that students will ask question or identify problem (define targeted creation) by awakening their curiosity through connecting what they do not know about the world to what they know already (background knowledge), and every new thing designed or every new solution found is just a novel combination of what already existed.

\section{Staging: improving quality, receiving recognition, and developing positive emotions frequently}

Designing learning activities is never a simple matter. In terms of IDC theory, there are three anchored concepts, each of which has three component concepts. Altogether, there are 12 concepts. Moreover, each concept can an into an individual concept and a group concept. For example, we can have individual interest and group interest, individual creation and group creation, and individual habit and group habit. The same applies to all component concepts; for example, we can have individual flow and group flow. Thus, conceptually, we may have 24 concepts in total. However, in practice, there can be no individual concept and there is only group concept associated with staging. This is because for staging there must be performers on the stage and audience on the floor.

For instance, in a dyadic interaction, if I talk to you, to be polite, you look at me and listen to me; thus, you become my stage. Conversely, if you talk to me, then I become your stage. In a group, if it is my turn to talk to the group, the group is my stage; if another member talks to the group, then I become part of this group member's stage. The same applies to the whole class and to some large online groups when the talk is directed at the whole class or the larger online audience. 


\section{Staging}

Staging, the third component of the creation loop, is the process where students demonstrate or explain their works to their peers at a stage. Staging aims to (i) improve the novelty and value of the products by getting feedback from peers; and (ii) receive social recognition and nurture positive social emotions such as gratitude and compassion. We discuss each of these below.

\section{Receiving peer feedback for improvement}

One of the important goals for creation is to attain quality, which is decided by novelty and value of the created product. Seldom is a product perfect when just created. Most likely, the product is still in a raw form. Improvement is an evolving process, and peer feedback is the main drive for improvement. Thus, in order to receive feedback, students need to be given a large amount of opportunities and places to explain and discuss their products.

Here, we take graduate students doing research as an example. When they begin their research, they need to acquire a lot of existing knowledge in their area and work on their projects. Then they may obtain some preliminary research results (i.e., their initial created products). To receive peer feedback, they present their results to their research group. Based on the feedback received, they continue their projects, improve their work, and get more results. To receive another round of feedback, they participate in local workshops and present their updated work. They keep on doing this and progress to presenting more work at international conferences and, finally, publishing their complete work in international journals. It is through the repeating process of staging and feedback from the audience that leads to the final improved product. It is important to note that the quality of a piece of research in a particular area depends on its novelty and value as defined by the research community in that area. The same situation exists in the context of schools. Aside from the teacher, it is the fellow classmates who constitute the relevant community to assess the novelty and value of their peers' creations. The fellow classmates care about their peers' work because they are also engaged in the same or similar activities. They are curious about and want to know what and how well their peers have done.

For improvement, combinational learning still plays an important role because students need to combine their peer feedback, which is essentially from their peers' background knowledge, with their own knowledge to enhance the product's novelty and value.

On the surface, it appears that in staging, it is the performer on the stage who would learn from the feedback of the audience on the floor. At the same time, however, the audience can also learn from the performer's demonstration. This reciprocal learning leads to the improvement and refinement of their constructed knowledge or artifacts. Suppose you are a researcher in a particular area and review a piece of research work. Very often your recommendation for this work may rely on whether you can learn from the research work. This is because if a product is not novel, you will not pay attention to it as it cannot arouse your curiosity. If it is not valuable, it is not worth spending time to learn about it at all. People tend to appreciate and learn things that are novel and valuable to them. For instance, if a product shows novelty and value, those who give feedback on it will learn something, because they combine their own 
knowledge with the knowledge illustrated in the product in order to understand and make sense of it. Giving feedback per se is a form of learning (Panadero, Jonsson, \& Alqassab, 2018).

Before we proceed further, we make two remarks. First, the communities giving feedback grow from an inner circle to a progressively expanded wider circle. This can start with peers in the same research lab, then academic peers in a local workshop, then participants in an international conference, and finally all potential readers in the world after the work is published in a journal. Similarly, students may initially discuss their created product within their inner circle such as their neighboring classmates and progress towards a wider circle such as students from different classes or schools or even with people across the globe through the Internet. Second, after receiving feedback, it is possible that the students may find that they need to make major revisions or even re-develop their product. This requires that they go through the creation loop again.

\section{Receiving social recognition and developing positive emotions}

Staging is not only to improve and advance creation, but also to receive social recognition. Shakespeare said, "All the world's a stage, and all the men and women merely players." The world is a stage, as it is there where you have an opportunity to share your abilities and outputs and demonstrate the value of your existence. Therefore, if you are a student in a school, the surrounding learning community becomes your stage. Indeed, there are many stages. When you talk to one of your classmates about your idea or illustrate an artifact made by you and to show politeness, your classmate must pay attention to you. They then become your stage (though a small stage). When you are on the stage, the onus is on you to attract the audience's attention by showcasing your created product. When your classmates are convinced of its novelty and value, they will then appreciate and recognize your effort and work. The same applies in the context of larger communities: when you talk to a group of classmates, they become your stage; when you talk to the whole class, everyone in the class becomes your stage; when you talk to a large online community, the community is your stage. Stage by stage, your creation is being recognized by your progressively enlarged communities.

Perhaps we can take the view that Maslow's hierarchy of human needs (Maslow, 1943) - physiological needs, safety needs, love needs, esteem needs, and self-actualization needs-are mostly related to how we are recognized by our community. Meeting these needs will inspire life to grow and encourage us to sustain our efforts. For example, to satisfy the two lower-level needs-safety and love-students may undergo imitational learning-exerting effort to show that they, just like everyone else, are members of the student community by speaking the same language, appreciating other classmates' achievements, and showing a willingness to learn from each other. To go beyond these two levels to satisfy the two higher-level needs-esteem and self-actualization-students may aim to produce something new and valuable to show to their peer community. This will demonstrate that they are not only a part of the community, but also, with their creations, are also able to contribute something worthy to be learned by the community. All these endeavors, however, require designing stages for students to demonstrate and convince the community the worthiness of their creation. 
In general, students need stages to demonstrate their competencies through their generated outputs, which will not be simply discarded after completion or assessment by examinations. Thus, the knowledge building paradigm that advances knowledge in the community can be considered as staging. Likewise, inquiry-based learning, problem-based learning, project-based learning, or design thinking activity that provides a real or virtual world context enable students to demonstrate and exemplify their work can also be considered as staging.

As described above, staging requires the created product or process worthy to be learned by the audience. Thus, if creating a product and demonstrating the accomplished product develop broader and deeper learning, it may be even more worthwhile to teach other peers how to create the product. Staging, if in the form of peer teaching, requires the peer teachers to develop techniques or products in a way that their peers can understand. Moreover, peer teachers need to construct questions for their peers to answer as well as to conduct verbal instruction, illustration, and explanations for better understanding. We consider this as another level of broader and deeper learning. Peer teaching brings learning within reach, fosters a sense of ownership, and increases joy in achievement (Chan, 2010; Chou \& Chan, 2016).

Besides building confidence and developing pride, the reciprocal roles of the performer and the audience in staging can nurture some important positive emotions. For example, if the stage is the class and the performers are a group of students, the group members need to help each other before going on the stage. To perform well, they realize the importance of giving constructive feedback while at the same time offering praise and encouragement to their peers. As a result of this process, they will develop positive emotions such as gratitude, compassion, and self-control that are crucial for attaining success in their future (DeSteno, 2018). Furthermore, frequent and continuous practice of staging will help students learn how to build lasting relationships with each other, making themselves better friends and better people and hence leading to a more meaningful and fulfilling life. We stress that success in learning is not only dependent on how students learn but can be very much influenced by their affective characteristics.

\section{Summary of staging}

To summarize, staging enables students to receive peer feedback to improve the novelty and value of their creations. Besides learning how to express ideas more effectively in the process, they can learn from each other, help each other, be recognized by each other, build their self-confidence, and develop positive emotions. Furthermore, by frequent and continuous staging, they progressively expand their relevant communities, sustain efforts to contribute to these communities, establish self-esteem, and hopefully attain self-actualization.

\section{Journey of increasingly challenging creations: successes, failures, reflections, and advancements}

Students usually start out ordinary and their creations may not necessarily bring value to the community. As time goes by, the creation loop iterating as a daily routine, in order to receive peer recognition and respect, students gradually realize the importance 
of novelty and value to their community in the staging component. Challenging creation tasks, probably inspired by students' insight or hinted by the teacher, may emerge. Representing goals that the students want to achieve and expecting contributions to their community, such challenges will lead the students to go on a journey filled with successes, failures, reflections, and improvements (Campbell, 1949).

In the journey of challenges, failures are inevitable unless students avoid creating anything at all. Every failure teaches students something. We see failure as an opportunity for students to learn about their strengths and weaknesses to further improve themselves. Embracing failure as part of learning is crucial for success. Experiments on productive failure show that failure will benefit longer-term success if students are left to resolve problems on their own (Kapur, 2008). When facing failure, students can learn to realize what problems will arise, understand their causes, and derive the solutions towards them.

Accepting and learning from failures are the fingerposts on the road to successful creations. When failure happens, students have to face it and reflect. Reflection crystallizes understanding of their journey-where they are and what they should do next. As Confucius said: "I reflect three times a day." During reflection, students diagnose the failure, go back where they were, and identify the cause of the failure. Along the way, they go to the imitating component again-developing skills or receiving advices from the teacher as well as getting feedbacks from their peers. With more skills or ideas acquired, students then develop a plan to revise their creation by recombining new elements with what they know before, execute the plan, measure the improvement, and advance forward in the journey. The cycle of the creation loop continues, and the knowledge of their evolving creations is being passed along to the community. Over time, when experiences are accumulated, successes are more than failures. Students grow stronger and keep striving for bigger challenges that demand harder efforts and greater determination to achieve what they want (Dalio, 2017). Tackling through a series of increasingly bigger challenges in the journey, students turn their interests into passions, creations into innovations, and habit-triggered efforts into goal-directed efforts (Chan et al., 2018) while the various loops continue to repeat.

In the rapidly changing world, every creation will either disappear or evolve. Most creations are imperfect but capable of advancement by recreation. In the process of success and failure, reflection and revision, and creation and recreation, students move forward for increasingly challenging creation tasks, developing resilience, grit, and perseverance (Duckworth, 2016; Niiya, Crocker, \& Bartmess, 2005; Wolters \& Hussain, 2015). With their achieved creations contributing to affiliated communities, they gradually build confidence, establish self-esteem, and, even to a small extent, realize selfactualization (Maslow, 1943). All in all, they foster a more positive attitude toward the future.

\section{Interest-driven design of creation}

IDC theory posits that the design of any learning activity should place "interest" as the first priority consideration (Chan et al., 2018; Wong et al., 2019). In terms of the three components of interest, we first consider how to trigger students' interest in the learning activity, how to immerse them in the learning activity, and how to extend their interest in the learning activity. In other words, we must first consider how the students 
learn with curiosity, in an immersive flow, and meaningfully for whatever learning activity they involve. Hence, we call such designs as "interest-driven." Let us consider an analogy to understand this intuitively. If we view a "learning activity," which constitutes a sequence of actions, as a "verb" in the English language, then "interest" (or "learning with interest') serves as an 'adverb' (such as "curiously," "immersively," and "meaningfully").

It should be noted that it is not necessary to consider all three components of interest, but at least one or two. For example, if students have developed their habits of book reading, arousing their curiosity in reading books is no longer necessary, and the focus of the design may then be on immersion and meaningfulness.

For the anchored concept creation described in this paper, we put forward that the learning activity, whether it is focused on a particular subject (e.g., reading as in "Case study 1: interest-driven creation loop design of MSSR" section), project (e.g., designing board games as in "Case study 2: interest-driven creation loop design of educational board games for design thinking" section), or program to address some issue (e.g., developing app as in "Case study 3: interest-driven creation loop design of computational making" section) can be considered as creation activity. Furthermore, a creation activity can be interpreted in terms of imitating, combining, and staging sub-activities or components. Each of these sub-activities, if needed, can be further constituted into subsub-activities (e.g., sub-components of imitating).

In IDC theory, we argue that learning or creating through imitating, combining, and staging are effective. However, effectiveness does not suffice in IDC theory. Each of the components-imitating, combining, and staging-must also be interest-driven. For example, students must be able to imitate curiously, immersively, and meaningfully.

Thus, what we have described above may represent an expansive view of the interestdriven design of creation activity. For the first level, we consider how to design an overall learning activity as a creation activity while at the same time consider how to engage students to learn with interest at this level. At the second level, we view the creation activity as a flow of sub-activities and consider how to design each of these sub-activities so that they are interest-driven. We continue this at the third level by decomposing some sub-activities into sub-sub-activities, if the overall learning activity is large, and at the same time ensuring that each design of the sub-sub-activities is interest-driven.

Most importantly, through such an interest-driven design of creation, if we can enable students to learn with interest in their daily routines, creation will become not only their habit, but also their individual interest or hobby. In short, when creation with interest repeats, creation will become a habit and a hobby (Chen et al., 2019). Students will then pursue their own learning by themselves and ultimately become lifelong interest-driven creators, as postulated in Chan et al. (2018).

\section{Case study 1: interest-driven creation loop design of MSSR}

In the introductory paper of IDC theory (Chan et al., 2018), we showcased the Modeled Sustained Silent Reading (MSSR) as an example of designing IDC-based learning activity. In this section, we examine the details of its creation loop design. MSSR is not simply about reading books. After students read books of their own choices, they proceed to pursuing two follow-up activities: writing recommendations for books they like and participating in book-talk with peers. The creation loop design is an inner-outer-loop 
design structure, with the outer-loop being the creation loop and the inner-loop being the interest loop. The outer loop design constitutes the three creation components: imitating, combining, and staging, while the inner-loop design involves how each of the creation components is spurred by triggering, immersing, and extending interest (Fig. 2).

For the outer loop design, the MSSR activity is first decomposed into three subactivities: reading books (imitating), writing recommendation (combining), and booktalk (staging). While reading books, students are inputting (imitating) knowledge from the books. Having acquired a fair amount of knowledge after reading a number of books, students usually feel the urge to share their favorite books with peers. This brings them to the outputting (combining) sub-activity: writing recommendations for books they enjoy reading. With My-Bookstore system (Fig. 3), a student draws a picture depicting the main theme of the book and, next to the picture, writes down text about the student's feelings or opinions of the book (Chien, Chen, \& Chan, 2017). With experience, some students will draw comic strips. To encourage and stimulate students to write down more texts, My-Bookstore also provides prompts such as "Who is the main character?" "What is the main character's problem?" "Summarize the plot." and "Why do I like this book?" (Atwell, 2007; p. 67). For higher-grade elementary or secondary school students, the prompts are words such as "summary" and "elaboration" that relate directly to the book, "connection," "inference," and "feeling" that link the content of the book with the student's experience, and "future reading" and "interesting questions" that promote more books for reading and stimulate exploration of issues aroused from the book (Keene \& Zimmermann, 2007; Pearson, Roehler, Dole, \& Duffy, 1992). As shown, making recommendations provide a space and mobilize processes that

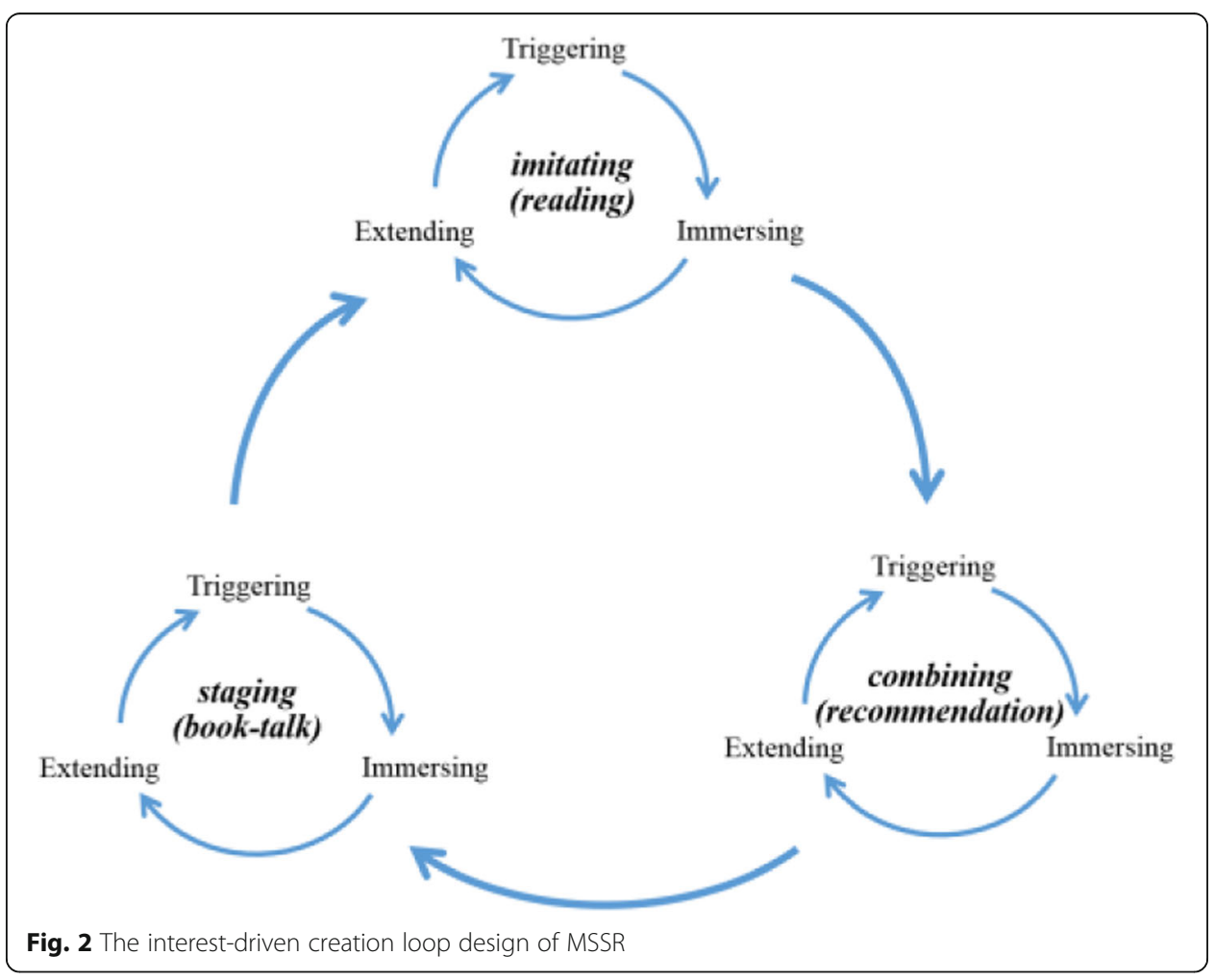




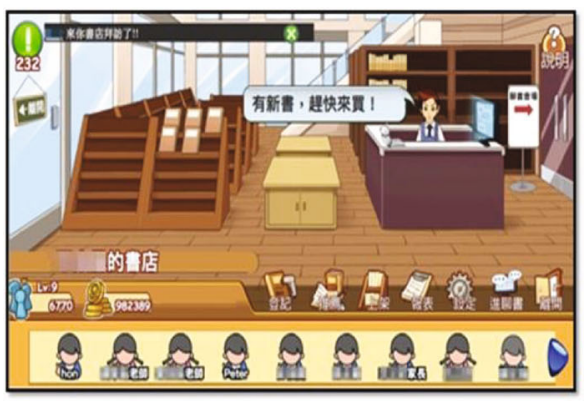

(a) My-Bookstore administration interface

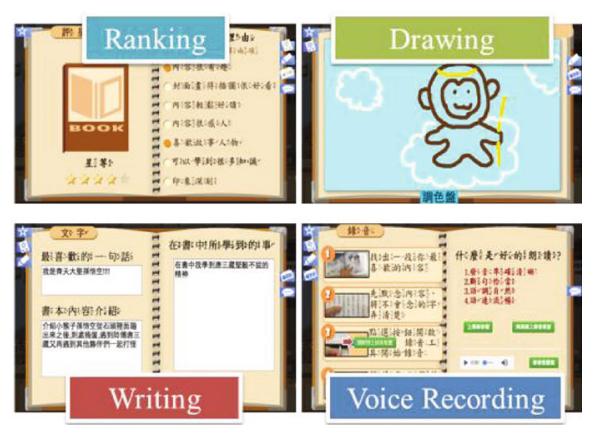

(b) Book recommendations

Fig. 3 My-bookstore system. a My-Bookstore administration interface. b Book recommendations

capitalize combining the essential content of the book and the student's background knowledge.

After writing recommendations in texts and pictures, the students then have something to talk about and need a place to recommend books to their classmates. Booktalk-a form of staging-arranged by the teacher is designed to provide such a feature. Some students, however, may be too shy to speak. Thus, they first conduct book-talk in pairs in which one student recommends a book to the other and vice versa; then, in groups in which each member takes turns recommending a book to the others in the group; and then in front of the class where recommendation is made to the whole class. Although we have not tried yet, in principle, students can conduct book-talk online to a broader audience. Through these processes, students not only reflect on their book recommendations but are also inspired by the feedback of their peers to expand and improve their recommendations. Book-talk brings life to good books and encourages the development of an intimate relationships between students and the books they like (Atwell, 2007, p. 67).

Besides revisiting the content of the book and preparing a "draft" manuscript for the book-talk sub-activity, the preparation of recommendations has the additional advantage of helping students develop writing skills. In some cases, when it is found that more than one student is recommending the same book, the teacher may suggest that they form a group and combine their individual recommendations into one recommendation (possibly using concept maps to integrate their ideas during the process). This group of students will thus go through the process of combining twice (i.e., one individually and one collaboratively). Conversely, other teachers might prefer that students proceed straight to the book-talk (staging) after reading a few books, thus omitting the written recommendations (combining). The rationale for this is that students can create what they want to recommend in their mind and output them verbally without preparing written recommendations first. This can be interpreted as putting combining and staging together. In general, the greater the effort put into recreating what has been acquired, the deeper the students' understanding of the book.

The outer creation loop design, in general, assumes that when students learn, in addition to exploring unknown territory, they also exploit what they know already (background knowledge). For learning, they need to revisit and reflect on what has been acquired. An effective way to do this is to recreate the crucial part of the process. Thus, 
in MSSR, simply reading books is not enough, students need to revisit the books they enjoy the most by recreating the crucial content of these books-through writing recommendations and getting peer feedback in book-talk. Creation is re-creation, through which students develop a deeper understanding and expand their knowledge.

\section{Reading book (imitating)}

Now, for the inner interest loop design, we consider, for each of the sub-activitiesreading book, writing recommendation, and book-talk-how the students' interest can be triggered, immersed, and extended, as shown in Fig. 2. For reading books (imitating), our earlier discussion of MSSR has already described how to trigger students' curiosity in books, how they become immersed in self-selected books with appealing and intriguing contents, and how their interest in books is extended by seeking other related books (Wong et al., 2019). Also, crucial to the success of this sub-activity is the teacher acting as a role model for other readers in the class. The teacher then sets a shining example for the students and leads the class by example (imitating the teacher's behavior).

\section{Writing recommendations (combining)}

For making recommendations (combining), students' interest is triggered by their own urge to share with their peers their enjoyable reading experience. Being social creatures, humans tend to seek opportunities to communicate about what they are concerned with. Students might also be curious to see how their peers respond to their discoveries about the books they like. In making recommendations, writing and drawing are considered immersive processes in which students express their thoughts in words and mental images in pictures, respectively. The prompts provided by My-Bookstore not only help students reflect what they have read (such as with summaries and elaborations), but also extend their interest by relating to their background knowledge, such as connection, inference, feeling, and interesting questions (Keene \& Zimmermann, 2007).

\section{Book-talk (staging)}

For book-talk (staging), the reason for students' interest to be triggered is the same as that for writing recommendations-the natural need to communicate with each other. However, differing from text or pictures, book-talk requires speech. With prepared recommendations, students easily become immersed in the book-talk activity with the content of their talking extending beyond that of a specific book, incorporating the student's background knowledge as well as the knowledge they have acquired from the books.

In general, the inner interest loop design assumes that, with appropriately designed activities, students' curiosity about different books is increased, a flow state is experienced, and the meaningfulness of their reading is enhanced while the scope of books they want to read is extended. Because developing interests is the principal consideration in designing any learning activity, the inner interest loop design may also be called interest-first design. Thus, once the MSSR activity has been decomposed into three sub-activities, design considerations are immediately directed towards the interest loop design for each sub-activity. The focus of the design is to make students 
experience a flow state while the goal of the design is to make the activity become part of students' individual interests or hobbies. For example, in the imitating sub-activity of MSSR - reading books - the focus is to get students deeply immersed in reading, while the goal is to develop their interest so that reading becomes one of their individual interests by repeating the interest loop. Once reading becomes an individual interest of the student, their interest is self-triggered, that is, they will take the initiative to read without the teacher's help. Ultimately, students become lifelong readers. Since lifelong learners must be lifelong readers, MSSR builds the foundation for lifelong learning. Likewise, we hope that students will develop lifelong habits of writing recommendations for books they love and carry out book-talk with friends and family members in their daily lives.

\section{Case study 2: interest-driven creation loop design of educational board games for design thinking}

The design thinking course for educational board games (DT-ETG) is our next example of illustrating IDC theory. An educational table game design course is not simply about students playing board games for fun. After the students play, they proceed to create games themselves but at the same time they tackle real-life learning problems around them. Similar to the MSSR case, the creation loop design for DT-ETG is interestdriven. The students go through the creation process involving the three consequent components: imitating, combining, and staging. During the interest-driven design process, students' interest is triggered, immersed, and extended gradually and continually by various incentives (as shown in Fig. 2).

In the first stage of design thinking, to engage students in the interest-driven design learning tasks, the teacher presents a case study with a real-life learning problem through a video clip or textual news. This triggers the students' interests to pursue more about this issue. Then, the teacher guides the students to think about real-life learning problems that happen around them, and then to choose one that they want to focus on for their design thinking project. After selecting the topic for their design thinking project, the students are guided to initiate their empathy to others, feel for them, and think from their angles. To conduct the context analysis and the needs analysis regarding the learning problem they have chosen, the students also search for related information for the learning problems, understand the causes of the learning problem, context and scenario of the learning problem, and think of possible methods to solve the learning problem. For example, choosing history learning as the problem, and then we define it as "learning history is boring since it depends heavily on memorization." Therefore, designing a board game for learning history is full of fun and lively, but at the same time, it elevates the cognitive thinking levels and enhances other abilities such as cooperation, communication, critical thinking, and computational thinking. Then, take the Age of Discovery as the time period as the design example, the design team searched the related information about it, and finally reached the decision to use trading in the Great Voyage time as the main topic for the board game. It should be noticed that, when empathizing with others, the students take ownership of the learning problem and gradually immerse in the design task.

Then, the DT-ETG course is composed by the following three consequent subactivities following the creation loop of design thinking: 


\section{Playing games (imitating)}

In this stage of design thinking process, the students are exposed to many different board games. While playing games, students are inputting (imitating) knowledge from the games they play. The more they play, the more they are exposed to different game mechanisms, and different kinds of mental and emotional states. Thus, they become immersed in the game contexts, and experience how the games present certain issues. The students would extend their interests to certain types of games or certain topic so that they hunt for more information regarding their design. Both the teacher and the students can initiate or introduce more relevant games to their issues. The students would at the same time come up with several possible solutions in terms of game design. This is the stage of divergent thinking. Back to the example of the Great Voyage board game, there are still many possible choices to decide on the context. Since spice is the most expensive cargo in the historical time and the most important trading goods, we choose it as the main theme of the board game, and name it Fragrance Channel. With the game experiences in this stage, the students' immersion in solving learning problem by designing board games is largely improved.

\section{Generating games (combining)}

Having acquired a fair amount of knowledge and experiences after playing a number of games, students usually feel excited to generate their own games to show off their own insights and talents due to a sense of superiority or seeking social recognition. In order to quickly come up with a main strategy for making games, they would choose a specific game to start with, and place necessary information pieces into the game to see if it fits. While coming up with the main structure of the game, there are normally issue-oriented problems that do not fit into the main structure. Therefore, this brings them to the convergent (combining) sub-activity when the students locate several possible game mechanisms they enjoy while playing, and then collect and integrate the game mechanisms for their issue-problems. With their design draft, the students draw the sketch of the game depicting the look of the game and its related board, cards, objects, and etc. As beginners, students would keep sharing their gaming experiences with each other without focus and not settling down on a main mechanism that can capture the spirit of the topic. To encourage students to more quickly come up with constructive design plans, they are given blank flashcards and white papers to create pretended games. The thinking tools generally help the students to be focused and with objects to think with. And even more, sometimes board game design tool packages are provided to the students which come with cards, stickers, dices, moving objects, and game coins. Drafting the look of games can give the students a better picture on deciding the combination of game mechanisms. It requires appropriate mechanisms to better present the issues that the game aims to deliver. In the example of Fragrance Channel (Fig. 4), it is decided to make it a strategic game with elements of role-playing. Each of the students would role-play one of the European countries, and complete their own tasks which have embedded conflicts between them. Each country is in different economic status, ship power, and goals. This encourages group cooperation and competition, providing a higher level of cognitive thinking and more social interactions. 


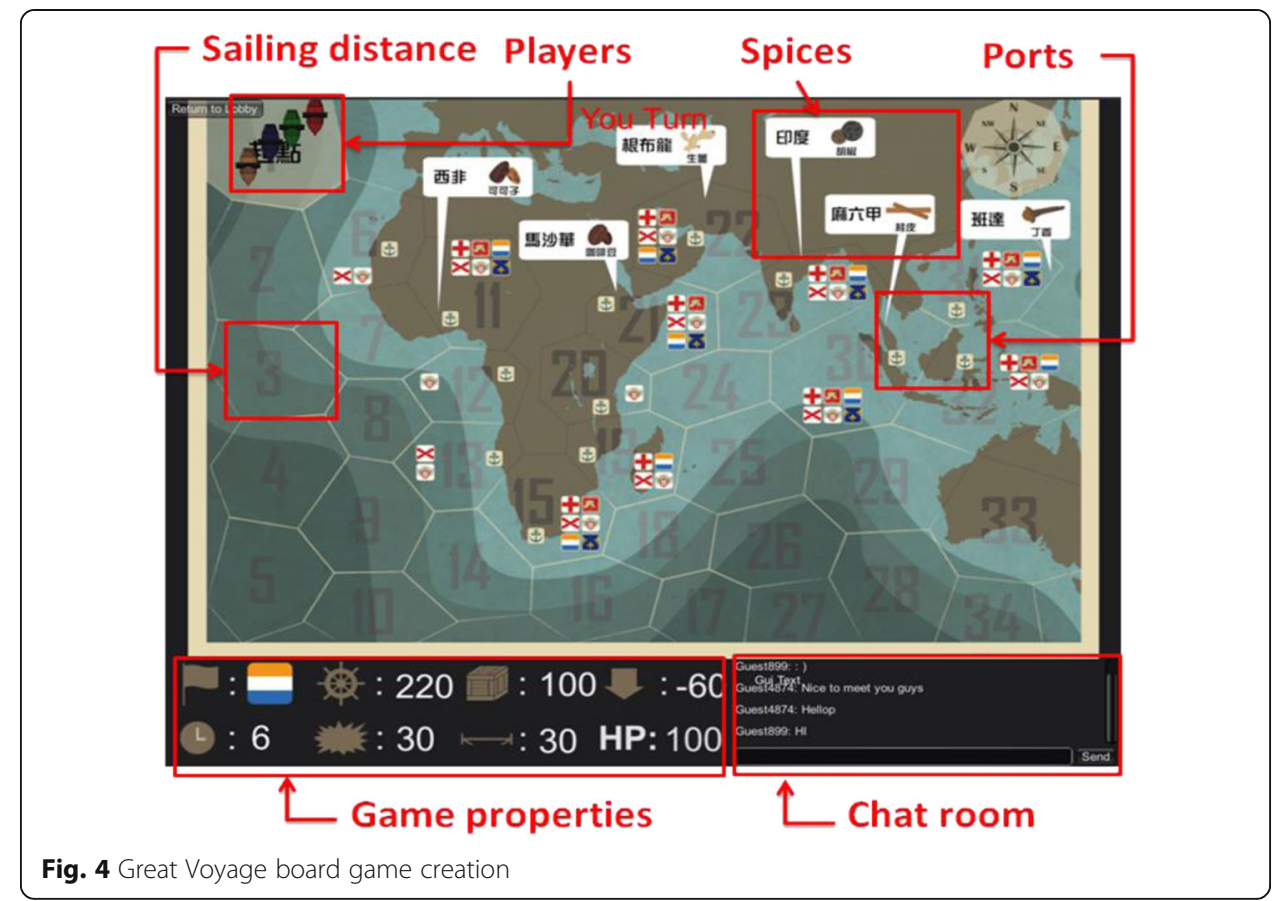

\section{Testing games (staging)}

After finalizing the game mechanisms, the students then have to produce the game prototype and showcase (stage) them to their classmates. Test-run the game is a form of staging. The teachers can make arrangements of the showcase agenda. Usually, we let half of the groups do the test-run with the rest of the groups as the player-testers; then reverse the groups in the second half of the class. Time control is one of the main tasks for the teacher since different games need a different length of time to complete. When they do the test-run, they need some time to be allocated for feedbacks. Comments about the game design, mechanism, and the interface are all welcomed. Techniques such as ORID focused discussion process are often used. It is for the users to give objective, reflective, interpretive, and decisional feedbacks so that the designers can receive both constructive suggestions and affectional feedbacks to the users. The teachers also need to give professional comments.

Through several trial plays, the game is tested to reach perfection and ready for final showcase (Fig. 5). After making several iterations, the students' creation ability and skills become stabilized. Because the students can observe the games their classmates created and have obtained comments from their peers, they became even more interested in making the games more sophisticated. This process would intrigue the students even more, causing them to redefine the problems and find more strategies to adjust the game. Besides having deeper understanding of the knowledge and the issues, the students further extend their interests in discovering more creative and better solutions for the learning problems after testing games (staging). The students then become self-pursuit learners, with their creations entering into a continuous iteration cycle of the creation loop until some satisfaction is achieved. 


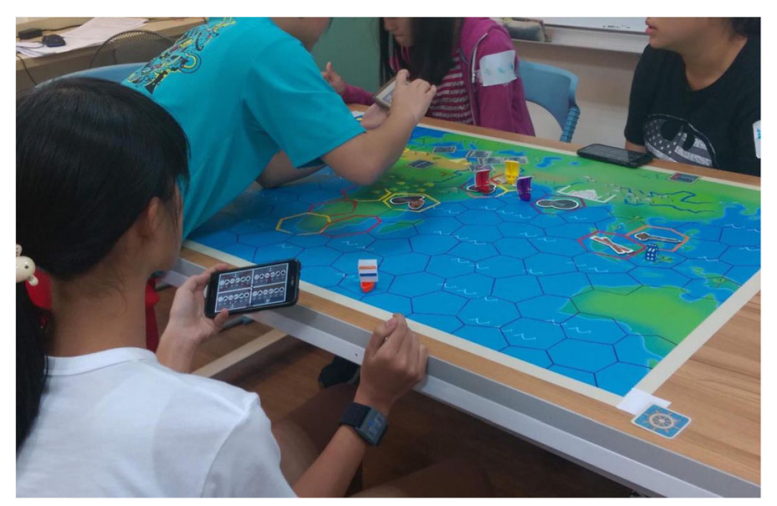

Fig. 5 Great Voyage board game in practice

Case study 3: interest-driven creation loop design of computational making

Within this broad context, another noteworthy initiative of using the creation loop design is to leverage computational making to boost the creation of knowledge and artifacts by students. In 2018, Singapore launched a Digital Readiness Blueprint to ensure that every citizen is equipped to live in a Smart Nation and has access to the tools and knowledge to benefit from technology. This push towards digital technology aims to deepen its citizens' technical capabilities, especially in key areas such as data science, artificial intelligence and cyber security (Smart Nation and Digital Government Office, 2018). One such program is an 8-month-long computational-making program for a group of about 50 secondary school students. It adopts an integration of design thinking, computational making and challenge-based learning approaches, so as to promote a holistic learning experience anchored in user-centered solutions that address real-world needs. Students will learn a coding language that enables them to develop apps on smartphones. They work in groups to take on a design challenge. These design challenges are scaffolded by design thinking with the aim to aid students' learning of computational concepts while also affording opportunities for individual expression and broadening perceptions of computing. At the end of the challenge, students must pitch their apps, explain the aesthetics and story behind the design of their app, and engage the audience in the process of developing their apps. Students would have to go through different levels of brainstorming and prototyping. Beyond coding, students have to hone their skills in story-telling and marketing. As shown in Fig. 6, two students in the computational making program have been working out an App called "moody" to trace daily moods through recording them comprehensively for the purpose of taking care of students' well-being and mental health. Users can view an overview of their moods, notes, and activities. The app can suggest tips to users to improve their moods. This idea for this app emerges from the creators' own personal need to improve their productivity and stress levels. Thus, their need to address a personal issue triggers interest and supports meaningful creation, as they go through cycles of design ideations before synthesizing an authentic solution.

Similar to MSSR, the creation loop design of the computational making program is also an inner-outer-loop design structure, with the outer-loop being the creation loop and the inner-loop being the interest loop. For the outer loop design, the computational making activity is decomposed into three sub-activities: Design-thinking \& 


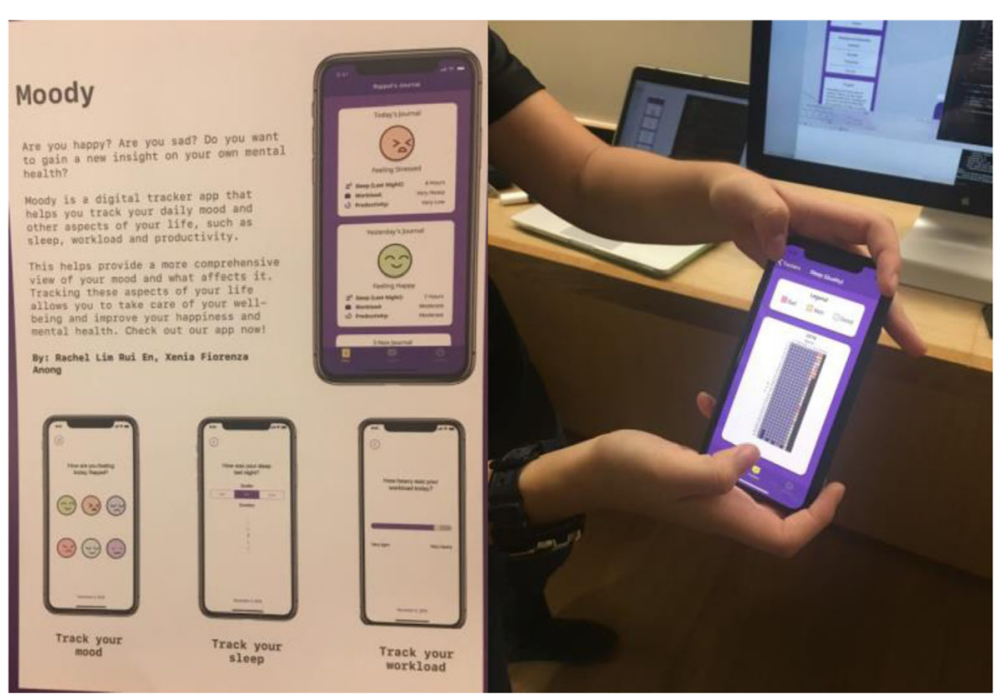

Fig. 6 A student-generated app "Moody" to trace daily moods

coding training (imitating), researching \& developing (combining), and publicizing \& marketing (staging).

\section{Design-thinking and coding training (imitating)}

During the training phase, students are exposed to a variety of basic knowledge on how to design and code app development. Students selected to be admitted to the program would generally possess certain basic and preliminary coding knowledge. At the very beginning of this program, they will be told of inspiring stories of app developers who are innovators in transforming people's lives and world. This serves as the starting point to intrigue them to learn and explore more ("triggering"). Some seasoned app developers including prominent young app entrepreneurs are brought in to provide motivational talks to the students. Next, the trainers will let them learn more about how to identify real-world needs, how to convert the needs into app design, and how to code to translate the design ideas into real app products, through well-selected specific examples. Students are guided to be immersed in designing and coding processes to enjoy the fun of being an app designer and implementer ("immersing"). Meanwhile, they can also request to deepen their knowledge with comprehensive readings on the related topics. Through this period of study of about four months, students' interests and capacities in design-thinking and coding are greatly improved, and they begin to express their willingness to pursue their own app development ("extending").

\section{Researching and developing (combining)}

In the researching and developing stage, students need to work together to start exploring the ideas of the app products they need to develop. At this stage, they would be exposed to many different types of apps, their functionalities, and their user-interfaces. They would need to do creative combining and synthesis of these ideas with other ideas arising from their own interest to create an innovative app idea. They first need to select the topics that are worth solving ("triggering"). They can propose several possible 
topics and conduct pragmatic evaluations to screen among these topics: which topics are of interest to them, and which topics can be solved by the current available resources and technical means. After topic selection, they begin to design their prototypes, considering how their app system interface would look like, which features should be included, and how these features could address real issues ("immersing"). Next, they start to divide their labor (usually they work in pairs) and apply the coding knowledge they learned to start the actual implementation on the app development platforms ("extending"). This is a challenging and iterative process that requires numerous debugging and do-overs, which demands the students to rely on their resilience to accomplish. The entire researching and developing process lasts for about four months. During this process, the role of trainers has been transformed to be more facilitationoriented, meaning they only need to provide certain advices and technical support when necessary. The students' creative re-combining efforts lead to some of these student-created apps. "Recollections" is an interactive photo album app that brings about new experiences and helps users to have fun in recalling and remembering special life moments. "MyReceipts" is to record and organize favorable receipts. "Cal" is a shared calendar app with a poll function to coordinate and set reminders of activities among people. All these apps have been inspired by their own living experiences that lead to creating their own creations paths or loops.

\section{Publicizing and marketing (staging)}

At this stage, students will have opportunities to publicize and market their apps. In the final phase of the project, a publicizing platform (a student-created apps fest) is held to allow all participating students to introduce their work to relevant stakeholders (parents, teachers, sponsors, researchers, etc.). Prior to the fest, they need to prepare posters to showcase the highlights of their work, and decide how to divide the work in their presentation ("triggering"). During the fest, they collaborate in pairs to convey to the audience about the issues that their apps are intended to solve, the design concepts behind the design, and how the apps can be actually used ("immersing"). This will be a rare opportunity to gain feedback and publicity for their apps. Exceptional studentcreated apps will be recommended to the authentic app market for the public to download online. Upon completion of the computational making program, any students have expressed their desire to continue their computing education or are piqued to design more such apps in the future, suggesting they have learned much from this one creation loop, and their interests are piqued to go for the next creation loop ("extending").

\section{Habit and the lifelong interest-driven creator}

Demonstrated by the above-described case studies, creation goes through the processes of imitating, combining, and staging. Thus, interest-driven creation also goes through the processes of interest-driven imitation, interest-driven combination, and interestdriven staging, which are as loops in practicing interest-driven creation. Creativity, referring to the ability of combining for a creation and elevating its quality-novelty and value-is also cultivated within the creation loop.

Now, from another perspective, let us consider what it means by a creator in the context of learning. If learning, as we posit, is creation and vice versa, then a learner must 
be a creator. Besides being able to create things, what we expect from a creator is that the learner has acquired an expertise of creation, at least to some degree. By this, it means that the learner creates frequently and has developed a mastery of the creation process. Thus, the learner can generate numerous creations with a number of them being high quality within the learners' relevant communities. Developing expertise in creation is essential in IDC Theory. For one reason, we put forward that students will excel in terms of learning performance, and thus, will be prepared for high-stakes examinations (Chan et al., 2018). This assumption is valid only if students have developed an expertise of creation so that they can perform well in the creation and hence learning.

Creation is a complex cognitive process, however. Developing an expertise in complex cognitive process demands many hours of purposeful and quality practices (Ericsson and Pool, 2007). This is only achievable through nurturing a habit of creation by practicing it in scheduled routines at schools and at home too. Since the anchored concept creation is comprised of imitating, combining, and staging components, developing expertise in creation can be more effective and manageable by separately forming habit of imitation (so that students can absorb abundant existing knowledge), habit of combination (so that students can generate ideas and artifacts prolifically), and habit of staging (so that students can learn from others constructively and receive social recognition frequently) and focusing on actively trying to go beyond their current capability of these three creation components (Ericsson, Krampe, \& Tesch-Romer, 1993). In terms of interest-driven creation as described in previous sections, these habits are also habit of interest-driven imitation, habit of interest-driven combination, and habit of interest-driven staging.

Also, since the creation process is interest-driven and since the students practice habitually, creation per se will become students' own individual interest (Hidi \& Renninger, 2006) or hobby. Then, driven by their own individual interest, they will develop a lifelong habit in pursuing their learning through creation. Thus, for teachers in the future, "teaching" is for the purpose of "not to teach," but for nurturing lifelong interestdriven creators by encouraging and facilitating students to develop their own interest and habit in creation. They may employ technology designed to support, sustain, and scale-up (3Cs) the nurturing. Finally, all the issues mentioned in this section will be further elaborated in the subsequent paper on habit and its formation (Chen et al., 2019).

\section{Conclusion and future work}

Imitating, combining, and staging form the core of the creation loop. Imitating concerns with knowledge absorption; combining speaks of knowledge generation; and staging talks about knowledge elevation and social recognition. Given its innate nature, imitating lays the foundation for creation. It occurs naturally especially when it is driven by interest and entails modeling where the learners use someone or something to copy. The act of imitation will progress to combining where the learners build on their existing concepts or artifacts to generate new ideas and insights. It is here that the learners start to create by selecting relevant features from existing concepts or artifacts. We stress that students themselves should be given the liberty to initiate and compose an intriguing creation of interest. Once the act of creating is accomplished, staging ensues where the learners are given opportunities to share their creations with their peers for receiving social recognition and constructive feedbacks. Reciprocal learning occurs 
when learners receive constructive feedback from their peers while at the same time their peers combine their existing knowledge with the new knowledge gained to make sense of the creation.

We view that learning is optimized at both the combining and staging components especially when students learn collaboratively in groups. The existence of peers as collaborative learners in the learning environment encourages students to engage with one another to clarify, discuss and evaluate ideas. The combinational learning comprising collaborators facilitates the acquisition of various background knowledge and wider experiences for students to develop new knowledge. When staging involves collaborative learners, this would entail students garnering richer feedback from peers and vice versa. While at the same time staging can shape positive affective characteristics that are vital attributes for students to face the unpredictable future.

There are other aspects of creation which need to be explored in further depth but are not elaborated in this paper due to length constraints. Nevertheless, we have illustrated why and how we view learning as creating and vice versa. Furthermore, we have presented the design tenets of nurturing creation and creativity in the language of the loops of imitating, combining and staging. Our intention is to explicate an expansive view of creation. This view needs to be positioned in theories of cognition, socialcultural theories of learning, frameworks for productive disciplinary engagement, and others. Doing so would present an expansive view that presents creation in its richness and arising from the fluid movement in both the outer and inner loops, as exemplified by the case of MSSR in the first case study. The intertwining of the creation loop with the interest loop in flexible ways is reflected in the second case study of students creating their own board game. The creation loops also embrace many examples of students creating through tinkering and computational making as reported in the literature, and exemplified by the case of computational making in the third case study.

The loops put the creation process in its epistemic plurality. It allows us to view the creation process as a continuum spanning different points of time, and to reflect creation in different grain sizes. The framework of loops permits analyzing students' development of interest and pursuit of goals, what they create in the pursuit, and how the learning experiences have been productive.

We can take the research forward in a few ways. One is to analyze contemporary accounts of creation and learning, and view these accounts from the perspectives of the three loops to validate and assess the adequacy, expressiveness, and gaps in the tenets of the loops. These accounts can come from publications or new research into sites where creation is thought to be pervasive. Yet, another approach is to take these tenets as the basis of design-based research, and frame research in terms of designing the interventions and affordances for creation, and collecting data for in-depth analysis. In short, we need compelling examples of interest-driven creation, and use them to test and refine the design tenets of IDC Theory. This will support us in the long-term goal of making a case for promoting and disseminating IDC-based learning (learning based on IDC theory), thus paving a way of educational reforms towards transformations in the world of education.

Also, in the past, we used to concern what learners learn (acquiring existing knowledge), we now also concern how they learn (being able to create knowledge themselves and developing twenty-first century skills in the process) and why they learn (being 
driven by their own interest in learning and receiving social recognition of their learning outcomes). Also, in the past, we used to ask have they learnt (concerning the result of their learning and hence examination), we now also ask can they learn (concerning the process and their capability of learning) and will they learn (concerning interest and habit of learning). However, for IDC theory, the first concern is why they learn, and the first question to ask is will they learn. Since learning is creation and vice versa, this means that the first concern and the first question to ask is whether students create with interest habitually.

To conclude, learning is not solely about knowledge acquisition but also entails more complex actions such as idea generation and artifacts creation. When students are engaged in these creation activities with interest on a daily routine, habits are then formed. The next paper of this thematic series will focus on habits, the third and final anchored concept of IDC theory. Finally, with all these deliberations, we hope IDC theory can inform an avenue towards future education in Asia and elsewhere.

\begin{abstract}
Authors' contributions
TWC was the main author of the paper who conducted the literature review, derived the key framework, and wrote the majority part of the paper. CKL was one of the anchor authors of IDC theory and wrote the "Conclusion and Future work" section in the paper. BC was one of the anchor authors of IDC theory and is the corresponding author of this paper. WC and LHW were the anchor authors of IDC theory and constitute the series of IDC papers with intertwining concepts. SLW, FYY, and JM were the early co-developers of IDC theory. They offered crucial ideas for us in developing the Creation and Creation Loop framework and were involved in tightening up the final version of this paper. CCL wrote part of the section on "combining." JLS and YTW wrote the "Case study 2: interest-driven creation loop design of educational board games for design thinking" section in the paper. SCK was one of the anchor authors and was involved in tightening up the final version of all the three case studies. LW wrote the "Case study 3: interestdriven creation loop design of computational making" section in this paper. TCC assisted the writing of the "Case study 1" section. CCYL, HC, ZHC, and CYC offered crucial ideas for us in developing IDC theory and Creation and the Creation Loop paper, and assisted us in refining the paper. All authors read and approved the final manuscript.
\end{abstract}

Funding

This is a conceptual paper. No research funding was involved.

Availability of data and materials

This is a conceptual paper. No empirical data was used for analysis and reporting in developing the paper.

Competing interests

The authors declare that they have no competing interests.

\begin{abstract}
Author details
${ }^{1}$ Graduate Institute of Network Learning Technology, National Central University, Taoyuan City, Taiwan. ${ }^{2}$ National Institute of Education, Nanyang Technological University, Singapore, Singapore. ${ }^{3}$ Graduate Institute of Learning and Instruction, National Central University, Taoyuan City, Taiwan. ${ }^{4}$ Faculty of Educational Studies, Universiti Putra Malaysia, Selangor, Malaysia. ${ }^{5}$ nstitute of Education, National Cheng Kung University, Tainan City, Taiwan. ${ }^{6}$ College of Education, Charles Darwin University, Casuarina, Australia. ${ }^{7}$ Department of Computer Science \& Information Engineering, National Central University, Taoyuan City, Taiwan. ${ }^{8}$ Department of Mathematics and Information Technology cum Director of Centre for Learning, Teaching and Technology, The Education University of Hong Kong, Ting Kok, Hong Kong. ${ }^{9}$ Department of Information Technology and Management, Tzu Chi University of Science and Technology, Hualien City, Taiwan. ${ }^{10}$ College of Nursing, National Taipei University of Nursing and Health Sciences, Taipei City, Taiwan. ${ }^{11}$ National Engineering Research Center for E-Learning, Central China Normal University, Wuhan, China. ${ }^{12}$ Graduate Institute of Information and Computer Education, National Taiwan Normal University, Taipei City, Taiwan. ${ }^{13}$ Department of Computer Science and Engineering, Yuan Ze University, Taoyuan City, Taiwan.
\end{abstract}

Received: 29 August 2019 Accepted: 22 November 2019

Published online: 30 December 2019

References

Allport, F. H. (1924). Social psychology. Cambridge, MA: Riverside.

Altshuller, G. (1992). And suddenly the inventor appeared: TRIZ, the theory of inventive problem solving. Technical Innovation Center, Inc

Anderson, L. W., \& Krathwohl, D. R. (2000). A taxonomy for learning, teaching, and assessing-A revision of Bloom's taxonomy of educational objectives. Allyn \& Bacon.

Atwell, N. (2007). The reading zone: How to help kids become skilled, passionate, habitual, critical readers. Scholastic Professional.

Bandura, A. (Ed.). (1971). Psychological modelling. New York: Lieber-Antherton. 
Bandura, A. (1986). Social foundations of thought and action: A social cognitive theory (pp. 47-105). Prentice Hall. Bear, M. F., Connors, B. W., \& Paradiso, M. A. (2016). Neuroscience: Exploring the brain (4th ed.). Wolters Kluwer. Bloom, B. S. (1956). Taxonomy of educational objectives: The classification of educational goals. Longman.

Blumenfeld, P. C., Soloway, E., Marx, R. W., Krajcik, J. S., Guzdial, M., \& Palincsar, A. (1991). Motivating project-based learning: Sustaining the doing, supporting the learning. Educational Psychologist, 26(3-4), 369-398.

Brown, T. (2009). Change by design: How design thinking transforms organizations and inspires innovation. New York: Harper Business. Campbell, J. (1949). A hero of thousand faces. New York: Pantheon Books.

Chan, T. W. (2010). How East Asian classrooms may change over the next 20 years? Journal of Computer Assisted Learning, 26(1), 28-52.

Chan, T. W., Looi, C. K., \& Chang, B. (2015). IDC theory: creation and the creation loop. In T. Kojiri, T. Supnithi, Y. Wang, Y. T. Wu, H. Ogata, W. Chen, S. C. Kong, \& F. Qiu (Eds.), Workshop Proceedings of the 23rd International Conference on Computers in Education (pp. 814-820). Hangzhou, China: Asia-Pacific Society for Computers in Education.

Chan, T. W., Looi, C. K., Chen, W., Wong, L. H., Chang, B., Liao, C. C. Y., et al. (2018). Interest-driven creator theory: Towards a theory of learning design for Asia in the twenty-first century. Journal of Computers in Education, 5(4), 435-461.

Chen, W. L., Chan, T. W., Wong, L. H., Looi, C. K., Liao, C. C. Y., Cheng, H., ... Gu, X. (2019). IDC Theory: Habit and the habit loop. Research and Practice in Technology Enhanced Learning. Manuscript in preparation.

Chien, T. C., Chen, Z. H., \& Chan, T. W. (2017). Exploring long-term behavior patterns in a book recommendation system for reading. Journal of Educational Technology \& Society, 20(2), 27-36.

Chou, C. Y., \& Chan, T. W. (2016). Reciprocal tutoring: design with cognitive load sharing. International Journal of Artificial Intelligence in Education, 26(1), 512-535.

Cohen, R. (2016). Secrets of swagger: How to own your cool in life and business (pp. 103). Greenleaf Book Group Press.

Collins, A., Brown, J. S., \& Newman, S. E. (1989). Cognitive apprenticeship: teaching the crafts of reading, writing, and mathematics. In L. B. Resnick (Ed.), Knowing, learning, and instructional: Essays in honor of Robert Glaser. Hillsdale, NJ: Erlbaum.

Csikszentmihalyi, M. (1996). Creativity: Flow and the psychology of discovery and invention. Harper Perennial.

Dalio, R. (2017). Principles: Life and work. Simon \& Schuster.

Dawkins, R. (1976). The selfish gene. New York: Oxford University Press.

DeSteno, D. (2018). Emotional success: The power of gratitude, compassion, and pride. Eamon Dolan/Houghton Mifflin Harcourt.

di Pellegrino, G., Fadiga, L., Fogassi, L., Gallese, V., \& Rizzolatti, G. (1992). Understanding motor events: A neurophysiological study. Experimental Brain Research, 91(1), 176-180.

Duckworth, A. (2016). Grit: The power of passion and perseverance. Scribner.

Eberle, R. (1972). Scamper: Games for imagination development. Texas: Prufrock Press.

Ericsson, K. A., Krampe, R. T., \& Tesch-Romer, C. (1993). The role of deliberate practice in the acquisition of expert performance. Psychological Review, 100(3), 363-406.

Ericsson, K. A., \& Pool, R. (2017). Peak: Secrets from the new science of expertise. Eamon Dolan Books.

Galton, F. (1869/1962). Hereditary genius: An inquiry into its laws and consequences. Cleveland, OH: Meridian Books.

Gazzaniga, M., Heatherton, T., \& Halpern, D. (2016). Psychological science (5th ed.). New York: W. W. Norton.

Hidi, S., \& Renninger, K. A. (2006). The four-phase model of interest development. Educational Psychologist, 41(2), 111-127.

Hmelo-Silver, C. E. (2004). Problem-based learning: What and how do students learn? Educational Psychology Review, 16(3), 235-266.

Holt, E. B. (1931). Animal drive and the learning process (Vol 1). New York: Holt.

lacoboni, M. (2008). Mirroring people: The new science of how we connect with others. Farrar, Straus and Giroux.

IMDA (2019, June 9). CODE@SG movement: Developing computational thinking as a national capability. Retrieved from http://www2.imda.gov.sg/program-listing/CodeSG

International Organization for Standardization. (2008). ISO/IEC 2382-36:2008 (en) Information technology — Vocabulary — Part 36: Learning, education and training.

Kapur, M. (2008). Productive failure. Cognition and Instruction, 26(3), 379-424.

Keene, E. O., \& Zimmermann, S. (2007). Mosaic of thought (2nd ed.). Heinemann.

Knobel, M., \& Lankshear, C. (2008). Remix: The art and craft of endless hybridization. Journal of Adolescent and Adult Literacy, $52,22-33$.

Kounios, J., \& Beeman, M. (2015). The eureka factor: Aha moments, creative insight, and the brain (pp. 9). Random House.

Lave, J., \& Wenger, E. (1991). Situated learning: Legitimate peripheral participation. Cambridge: University of Cambridge Press.

Lessing, L. (2008). Remix: Making art and commerce thrive in the hybrid economy. New York: Penguin Press.

Linkner, J. (2011). Disciplined dreaming: A proven system to drive breakthrough creativity. San Francisco, CA: Jossey-Bass.

Liu, C. C., Chen, W. C., Lin, H. M., \& Huang, Y. Y. (2017). A remix-oriented approach to promoting student engagement in a long-term participatory learning program. Computers \& Education, 110, 1-15.

Liu, C. C., Tao, S. Y., Chen, W. H., Chen, S. Y., \& Liu, B. J. (2013). The effects of a creative commons approach on collaborative learning. Behaviour \& Information Technology, 32(1), 37-51.

Lombroso, C. (1984/1891). The man of genius. New York: Garland Publishing.

Maslow, A. H. (1943). A theory of human motivation. Psychological Review, 50(4), 370-396.

Meltzoff, A. N., \& Moore, M. K. (1977). Imitation of facial and manual gestures by human neonates. Science, 198, 74-78.

Michalko, M. (2001). Cracking creativity: The secrets of creative genius. Ten Speed Press.

Mohaghegh, D. M., \& McCauley, M. (2016). Computational thinking: The skill set of the 21st century. International Journal of Computer Science and Information Technologies, 7(3), 1524-1530.

Niiya, Y., Crocker, J., \& Bartmess, E. N. (2005). From vulnerability to resilience: Learning orientations buffer contingent selfesteem from failure. Psychological Science, 15(12), 801-805.

Panadero, E., Jonsson, A., \& Alqassab, M. (2018). Providing formative peer feedback: what do we know? In A. A. Lipnevich, \& J. K. Smith (Eds.). The Cambridge handbook of instructional feedback (pp. 409-431). Cambridge University Press.

Pearson, P. D., Roehler, L., Dole, J., \& Duffy, G. (1992). Developing expertise in reading comprehension. In S. J. Samuels \& A. E. Farstrup (Eds.), What research has to say about reading instruction (2nd ed., pp. 145-199). Newark, DE: International Reading Association. 
Pedaste, M., Mäeots, M., Siiman, L. A., de Jong, T., van Riesen, S. A. N., Kamp, E. T., et al. (2015). Phases of inquiry-based learning: definitions and the inquiry cycle. Educational Research Review, 14, 47-61.

Piaget, J. (1951). Play, dreams, and imitation in childhood. New York: Norton.

Poincaré, H. (2015/1908). The foundations of science (pp. 387). Cambridge University Press.

Puentedura, R. R. (2014). SAMR and TPCK: A hands-on approach to classroom practice. Retrieved from http://www.hippasus com/rrpweblog/archives/2014/12/11/ SAMRandTPCK_HandsOnApproachClassroomPractice.pdf

Rizzolatti, G. (2014). Imitation: Mechanisms and importance for human culture. Advances and Perspectives in Neuroculture, 25(3), 285-289.

Rizzolatti, G., \& Fabbri-Destro, M. (2010). Mirror neurons: From discovery to autism. Experimental Brain Research, 200(3-4), 223-237.

Rothenberg, A. (1996). The Janusian process in scientific creativity. Creativity Research Journal, 9(2-3), 207-231.

Sawyer, K. (2012). Explaining creativity: The science of human innovation (2nd ed.) (pp.19). Oxford University Press, Inc.

Sawyer, K., (2013). Zig zag: The surprising path to greater creativity (pp. 129). Jossey-Bass.

Scardamalia, M., \& Bereiter, C. (2003). Knowledge building. In Encyclopedia of education (2nd ed.) (pp. 1370-1373). New York, NY: Macmillan Reference.

Scardamalia, M., \& Bereiter, C. (2006). Knowledge building: Theory, pedagogy, and technology. In K. Sawyer (Ed.), Cambridge handbook of learning sciences (pp. 97-118). New York: Cambridge University Press.

Simonton, K. D. (1988). Scientific genius: A psychology of science (pp. 88-91). New York: Cambridge University Press.

Sternberg, R. J. (Ed.). (1999). Handbook of creativity. Cambridge University Press.

Tabesh, Y. (2017). Computational thinking: A 21st century skill. Olympiads in Informatics, 11, 65-70.

Tan, S. C., So, H. J., \& Yeo, J. (Eds.). (2014). Knowledge creation in education. Singapore: Springer.

Tissenbaum, M., Sheldon, J., \& Abelson, H. (2019). From computational thinking to computational action. Communications of the ACM, 62(3), 34-36

Ward, T. B., \& Kolomyts, Y. (2010). Cognition and creativity. In J. C. Kaufman, \& R. J. Sternberg (Eds.). The Cambridge handbook of creativity (pp. 93-112). Cambridge University Press.

Weisberg, R. W. (1986). Creativity: Genius and other myths. New York: W. H. Freeman.

Wenger, E. (1998). Communities of practice: Learning, meaning, and identity. Cambridge University Press.

Wolters, C. A., \& Hussain, M. (2015). Investigating grit and its relations with college students' self-regulated learning and academic achievement. Metacognition and Learning, 10(3), 293-311.

Wong, L. H., Chan, T. W., Chen, W., Looi, C. K., Chen, Z. H., Liao, C. C. Y., ... Wong, S. L. (2019). IDC Theory: Interest and the interest loop. Research and Practice in Technology Enhanced Learning. Manuscript in preparation.

\section{Publisher's Note}

Springer Nature remains neutral with regard to jurisdictional claims in published maps and institutional affiliations.

\section{Submit your manuscript to a SpringerOpen ${ }^{\circ}$ journal and benefit from:}

- Convenient online submission

- Rigorous peer review

- Open access: articles freely available online

High visibility within the field

- Retaining the copyright to your article

Submit your next manuscript at $>$ springeropen.com 